\author{
Alicja Waszkiewicz-Raviv \\ Wydział Dziennikarstwa, Informacji i Bibliologii \\ Uniwersytet Warszawski
}

\title{
ALFABETYZM WIZUALNY ODBIORCÓW DZIAŁAŃ PR W PRZESTRZENI MEDIALNEJ - POSTULATY
}

\section{Abstract \\ VISUAL LITERACY OF PR RECIPIENTS IN THE MEDIA SPHERE - ANXIETIES}

In the times of the image culture, an extremely important element of media education is the dissemination of knowledge about the specifics and determinants of visual communication in the media, especially those inspired by public relations tools. The world of influencers, youtubers and video bloggers is often the environment for the dominant reception of media messages among kids and young adults, especially those with smartphones. The paper aims to outline areas in which knowledge about imaging has its application in the area of media education, and to provide examples of PR activities shaping the reception in these fields. Visual media education should develop the visual literacy of recipients including knowledge on PR visual activities. Through the intentional and creative use of visual competencies, the recipient can better communicate with others. At the same time, the awareness of the participation of PR tools in media content is related to social attitudes of children and young people, especially to the consumption and market behaviours.

Key words: visual literacy, public relations, iconosphere, media education 
Albowiem awans medialnego świata obrazów do rangi właściwej rzeczywistości sprzyja - choćby dlatego, że rzeczywistość ta jest łatwo dostępna i tak łatwo można niq operować - przekształcaniu człowieka $w$ monadę $w$ sensie indywiduum wypetnionego obrazami, a pozbawionego okien ${ }^{1}$.

Wolfgang Welsch

\section{Wprowadzenie}

W czasach kultury obrazu niezwykle istotnym elementem edukacji medialnej jest szerzenie wiedzy dotyczącej specyfiki i uwarunkowań komunikacji wizualnej w mediach, szczególnie tej inspirowanej narzędziami public relations. Świat influencerów, youtuberów i wideoblogerów jest dziś często środowiskiem dominującego odbioru komunikatów medialnych wśród nieletnich, zwłaszcza młodzieży zaopatrzonej w smartfony. Niniejszy artykuł, opierając się na międzydziedzinowej analizie literatury, ma na celu nakreślić obszary, w których wiedza na temat obrazowania znajduje swoje zastosowanie w edukacji medialnej, oraz podać przykłady działań PR kształtujące recepcję na tych polach. Wizualna edukacja medialna bowiem powinna rozwijać alfabetyzm wizualny odbiorców z uwzględnieniem wiedzy na temat PR w mediach.

Międzynarodowe Stowarzyszenie Alfabetyzacji Wizualnej (Visual Literacy Association) uznaje za alfabetyzm wizualny "grupę kompetencji wizualnych, które może rozwinąć każdy człowiek poprzez patrzenie i równoległe integrowanie innych doświadczeń sensorycznych. Rozwój tych kompetencji jest fundamentalny dla prawidłowego przyswajania wiedzy. Umożliwiają rozróżnianie oraz interpretowanie czynności, przedmiotów i/lub symboli wizualnych, zarówno naturalnych, jak i nienaturalnych, które napotykamy w naszym otoczeniu”2. Jest to termin, który budzi kontrowersje, najczęściej bowiem kompetencje komunikacyjne kojarzą się z umiejętnością pisania i czytania, niektórzy zaś uznają słowo „alfabetyzm” łączone z przymiotnikiem „wizualny” za terminologiczny oksymoron, gdyż pierwsze określenie dotyczy liter, a drugie obrazów ${ }^{3}$. Na owe kompetencje wizualne powinny się składać: wiedza z zakresu percepcji wzrokowej (np. zastosowanie iluzji optycznych w plakatach), wykorzystanie nowych technologii do obróbki obrazów (np. filtry na Instagramie idealizujące influencera) oraz rozwój strategicznych umiejętności koniecznych do interpretowania obrazów (np. pozycjonowanie obrazów

1 W. Welsch, Estetyka i anestetyka, [w:] R. Nycz (red.), Postmodernizm. Antologia przekładów, Wydawnictwo Baran i Suszczyński, Kraków 1998, s. 526.

${ }^{2}$ International Visual Literacy Association, https://ivla.org/new/what-is-visual-literacy-2/ (dostęp: 10.03.2018).

${ }^{3}$ Kwestia ta wynika także z niejednoznaczności przekładu z angielskiego, gdzie terminy media literacy i media competence bywają używane zamiennie. Por. B.A. Chauvin, Visual or Media Literacy?, „Journal of Visual Literacy” 2016, t. 23, nr 2, s. 119-128. 
przez wyszukiwarki zgodne z interesem korporacji). Przez intencjonalne i kreatywne użycie tych kompetencji odbiorcy mogą komunikować się z innymi, natomiast ich twórcze użycie powiększa grono świadomych odbiorców treści medialnych. Agnieszka Ogonowska posługuje się pojęciem „wrażliwość ikoniczna”, a kompetencje wizualne definiuje właśnie jako połączenie komponentów: kognitywnych, technicznych oraz społecznych ${ }^{4}$. Autorka słusznie podkreśla wagę różnych form socjalizacji i edukacji dostępnych jednostce, w tym także rolę instytucji społecznych wpływających na poziom opisywanej kompetencji, tj. szkół, muzeów, wystaw oraz przestrzeni medialnych służących ekspozycji i dystrybucji przekazów ikonicznych ${ }^{5}$. W zakresie przedmiotowym niniejszego opracowania zwrócono uwagę na udział narzędzi PR w mediasferze, w rezultacie silnie powiązanych z postawami społecznymi, zwłaszcza konsumpcyjnymi, dzieci i młodzieży.

Rozwój dziedziny, jaką jest edukacja medialna, zawdzięczamy współcześnie coraz szybszym przemianom technologicznym w sferze mediów oraz towarzyszącym im przemianom społeczno-kulturowym. W ostatnich latach liczne publikacje Agnieszki Ogonowskiej, Grzegorza Ptaszka ${ }^{6}$ i Mirosława Filiciaka ${ }^{7}$ dotyczą wymiarów psychologicznych oraz socjologicznych tego zjawiska, dodatkowo szczególny nacisk jest kładziony na kwestię cyfryzacji jako trend dominujący w uwarunkowaniach edukacji medialnej ${ }^{8}$. Autorzy ci podkreślają zagadnienie dostępności technologii mobilnych, wskazują na zagrożenia w postaci uzależnień oraz rozpadu więzi i relacji społecznych. "Cyfrowi tubylcy” (digital natives) i „cyfrowi imigranci” (digital immigrants) stają się coraz częściej określeniami podkreślającymi społeczną stratyfikację, podziały, a nawet przepaść między aktywnymi (w domyśle: kompetentnymi) użytkownikami oraz biernymi odbiorcami, gorzej radzącymi sobie w świecie online. Silne w polskim środowisku akademickim zajmującym się edukacją medialną są także nurty: medioznawczy ${ }^{9}$, opisujący mechanizmy komunikacji medialnej i skutki jej wpływu, pedagogiczny ${ }^{10}$, zwracający między innymi uwage na rolę instytucji edukacyjnych w obszarze kształtowania wiedzy na temat mediów,

${ }^{4}$ A. Ogonowska, Kultura, komunikacja i kompetencja wizualna w kontekście wybranych zagadnień współczesnej humanistyki, „Zeszyt Naukowy Wyższej Szkoły Zarządzania i Bankowości w Krakowie. Nowe Media: Edukacja - Polityka - Ekonomia - Kultura” 2012, nr 26, s. 113-143.

5 Tamże, s. 61-62.

${ }^{6}$ A. Ogonowska, G. Ptaszek (red.), Edukacja medialna w dobie współczesnych zmian kulturowych, społecznych i technologicznych, Impuls, Kraków 2015.

7 M. Filiciak (red.), Młodzi i media. Nowe media a uczestnictwo w kulturze, Raport Centrum Badań nad Kulturą Popularną SWPS, Warszawa 2010.

${ }^{8}$ D. Gałuszka, Gry wideo w środowisku rodzinnym. Diagnoza i rekomendacje, Libron, Kraków 2017; P. Siuda, G.D. Stunża, A.J. Dąbrowska, M. Klimowicz, E. Kulczycki, R. Piotrowska, E. Rozkosz, M. Sieńko, K. Stachura, Dzieci sieci 2.0. Kompetencje komunikacyjne młodych, Instytut Kultury Miejskiej, Ośrodek Badań i Analiz Społecznych, Gdańsk 2013.

9 T. Goban-Klas, Edukacja medialna. Społeczeństwo medialne, WSiP, Warszawa 2005.

${ }_{10}$ Z. Melosik, T. Szkudlarek, Kultura, tożsamość i edukacja. Migotanie znaczeń, Impuls, Kraków 1998; W. Strykowski, Media i edukacja, „Edukacja Medialna” 1996, nr 1; M. Kąkolewicz, Edukacja medialna - nowa dziedzina kształcenia, „Edukacja Medialna” 1999, nr 4. 
oraz kulturoznawczy ${ }^{11}$, opisujący korzystanie z mediów jako praktykę społeczną. Warto również wskazać nurt teologiczny i filozoficzny, w tym publikacje naukowe na łamach periodyków „Kultura - Media - Teologia” UKSW czy „Biuletyn Edukacji Medialnej” KUL, uszczegółowiające perspektywę aksjologiczną.

Paradygmat społeczno-kulturowy zdaje się więc dominować $\mathrm{w}$ polskim piśmiennictwie z zakresu edukacji medialnej, czego konsekwencją może być niewystarczająco pogłębiony aspekt ekonomiczny, a szczególnie uwarunkowania marketingowe zawartości mediów. Zwłaszcza zaś bardziej nieuchwytne dla mniej wprawnego odbiorcy treści public relations, z którymi dzieci i młodzież mierzą się w swej codzienności medialnej, znajdują niedostateczną reprezentację w publikacjach na temat edukacji medialnej. Jerzy Olędzki i Dariusz Tworzydło podkreślają, że większość zawartości współczesnych mediów jest umotywowana oraz inspirowana, a wręcz tworzona przez specjalistów od $\mathrm{PR}^{12}$. Badania Olędzkiego dodatkowo wskazują na liczne zagrożenia, jakie się z tym wiążą, oraz negatywną konotację skrótu PR w polskim społeczeństwie ${ }^{13}$. Istnieją zatem podstawy, by z niechęcią traktować działania PR-owców na rynku medialnym - zarzuca się im zbyt silny wpływ na dziennikarzy i ich pracę. Ciekawe badania na ten temat przeprowadził Przemysław Szews, uwzględniając aspekt edukacji młodych PR-owców w samym środowisku dziennikarzy ${ }^{14}$. Jest to jednak debata, której korzenie sięgają głębokich zmian roli audytorium medialnego i transformacji jego członków z obywateli w konsumentów. Współczesne media to przedsiębiorstwa, a jeśli ich oferta ma przynosić zysk, wówczas to treści istotne z marketingowego punktu widzenia, te, które lepiej się sprzedają oraz „klikają” w Internecie, są preferowane przez nadawców instytucjonalnych, funkcjonujących w warunkach wysokiej konkurencyjności. Nic więc dziwnego, że w mediach dominuje rozrywka inspirowana przez cele komercyjne organizacji.

Olędzki zauważa, że „niezbyt chlubna sława otaczająca działania marketingowe zostaje przeniesiona na public relations" ${ }^{\prime 1}$. A przecież PR nie jest tożsamy z marketingiem. Jest funkcją zarządzania komunikacją organizacji na wolnym rynku, którą można wykorzystać do prowadzenia dialogu z publicznościami oraz do intensyfikacji kontaktów z interesariuszami w celu osiągnięcia obopólnych korzyści zarówno dla nadawców, jak i odbiorców komunikatów. Co więcej, w dobie mediów społecznościowych ci ostatni sami często stają się nadawcami, jak w przypadku blogerów,

${ }^{11}$ G.D. Stunża (red.), Edukacja kulturalna i medialna. Nowe trendy i wyzwania, Edukatormedialny.pl, Instytut Kultury Miejskiej, Gdańsk 2014.

${ }_{12}$ J. Olędzki, D. Tworzydło, Public relations. Znaczenie społeczne i kierunki rozwoju, WSIiZ, Wydawnictwo Naukowe PWN, Rzeszów-Warszawa 2010.

${ }^{13} \mathrm{~J}$. Olędzki, O wizerunku public relations $w$ polskim społeczeństwie, „Studia Medioznawcze” 2016, nr 1/64, s. 23-35.

14 P. Szews, Dziennikarz i PR-owiec: połączenie niemożliwe i nieetyczne?, „Studia Medioznawcze" 2015, nr 1/60, s. 33-42.

15 J. Olędzki, O wizerunku public relations $w$ polskim społeczeństwie, „Studia Medioznawcze” 2016, nr 1/64, s. 35. 
vlogerów, youtuberów. Zawartość zaś, którą tworzą, bywa inspirowana komunikatami organizacji. Relacje z mediami są więc istotnym, choć tylko jednym $\mathrm{z}$ wielu narzędzi PR wykorzystywanym do budowania relacji z grupami odbiorców. Większość z nich ma swój wymiar estetyczny i przebiega kanałem wizualnym. Relacje $\mathrm{z}$ mediami koncentrują się na interakcji praktyki public relations $\mathrm{z}$ różnymi mediami w celu informowania społeczeństwa o kampanii organizacji. Jak podkreślają Richard Waters, Natalie T.J. Tindall i Timothy S. Morto, po kilkudziesięciu latach badań naukowych nad teorią agenda setting i związanych z nią badań nad wpływem samego PR na zawartość mediów istnieje wiele dowodów, że sposób informowania przez media ma wpływ na to, jak społeczeństwo postrzega różnorodność kwestii społecznych (ang. issues) oraz interesy organizacji ${ }^{16}$. Ale dzisiejszy PR to dużo szersze spektrum kanałów komunikacji.

\section{Wizualne public relations w mediach}

Współczesny PR zmienia się wraz z rozwojem samych mediów. Anna Miotk dostrzega, że ewolucja technologii internetowej, zmiany rynkowe, pojawienie się prosumenta, influencera oraz nowych metod komunikacji prowadzonej 24 godziny na dobę i na wielu kanałach doprowadziło do ewolucji PR, jego narracji, treści i technik $^{17}$. Jedną z nich jest silny trend wizualizacji materiałów kierowanych do mediów. Obecnie specjalista od PR jest współproducentem różnych typów treści - to kompozytor (oprawa muzyczna konferencji prasowej), choreograf (eventy), a zwłaszcza grafik (prezentacje, memy korporacyjne). Badania przeprowadzone przez autorkę wskazują na trend intensyfikacji komunikacji obrazami we współczesnych mediach i PR. Specjaliści w owych dziedzinach w przeważającej większości dostrzegają zmiany w metodach przygotowywania materiałów dla mediów, związane $\mathrm{z}$ dominacją przekazów wizualnych nad tekstowymi ${ }^{18}$. Obecnie niezwykle istotna jest umiejętność tworzenia obrazów, które potrafią przekazać informacje w sposób estetyczny i znaczący, ważna jest także zdolność interpretacji owych przekazów wizualnych przez odbiorcę o kompetencjach pozwalającej na dekodowanie

16 C.M. Howard, W.K. Mathews, On Deadline: Managing Media Relations, Waveland Press, Prospect Heights, IL 2006.

17 A. Miotk, Nowy PR. Jak internet zmienił public relations, Słowa i Myśli, Lublin 2016, s. 191-222.

18 A. Waszkiewicz-Raviv, Niepublikowany raport z badań „Materiały wizualne w PR kultury obrazu" przeprowadzonych na próbie specjalistów PR i zarządzania mediami $(\mathrm{N}=48)$ w czasie ogólnopolskiego seminarium „Kondycja branży PR w Polsce” w listopadzie 2017 roku. Powyżej 80\% badanych potwierdziło dominację przekazów wizualnych nad tekstowymi. Procent młodych adeptów PR w wieku 20-35 lat zawsze wykorzystujących materiały graficzne wynosił aż 30\%. 65\% specjalistów powyżej 36. roku życia korzysta z materiałów wizualnych często. Można więc założyć, że trend ten będzie się jedynie nasilał wraz ze zdobywaniem doświadczenia przez adeptów i wobec umacniającej się ikonosfery w kulturze oraz obrazów w medialnych reprezentacjach. 
i umożliwiającej zrozumienie. W tym obszarze zachodzą na siebie kompetencje nadawcy (PR-owca) oraz odbiorcy, przedstawiciela publiczności z jego alfabetyzmem wizualnym.

Współczesna zintegrowana komunikacja marketingowa (ZKM) ma afirmatywny stosunek do procesów indywidualizacji. Promowanie nieograniczonej wolności dostępu do wizerunków, obrazów swoich (np. selfie) i świata często redukuje odbiór komunikatów wizualnych do szybkiej oceny ich estetycznego wymiaru. Public relations rozumiane jako komunikacja instytucjonalna, intencjonalna, zarówno informacyjna, jak i perswazyjna, według teoretyków winna odróżniać się od marketingu zorientowanego na sprzedaż właśnie swoim wymiarem aksjologicznym ${ }^{19}$. PR funkcjonuje bowiem w przestrzeni społeczno-kulturowej jako forma dialogiczna, tym samym zakłada konieczność zadbania o odbiorcę, nie zaś jedynie o jednokierunkową i jednowymiarową promocję oferty organizacji. Model transmisyjny, stawiający na rozgłos (ang. publicity), jest ograniczający, datowany w swoich początkach na koniec XIX wieku ${ }^{20}$, dziś ma ewentualnie zastosowanie w branży rozrywkowej, natomiast $\mathrm{w}$ dobie interakcji ciągłych $\mathrm{w}$ mediach społecznościowych jest przeżytkiem. Tacy badacze jak Lee Edwards ${ }^{21}$ czy Derina Holtzhausen ${ }^{22}$ podkreślają rolę PR-u w debacie społecznej, w wyjaśnianiu praw rządzących nie tylko danym sektorem rynku istotnego dla organizacji, ale też szerzej pojmowanej wspólnoty komunikujących i odbiorców, w szczególności w szerzeniu wiedzy i promowaniu aktywizmu społecznego ${ }^{23}$. Współcześni teoretycy PR postulują poszukiwanie konsensusu i symetrii jako nadrzędny paradygmat wyróżniający PR spośród narzędzi komunikacyjnych organizacji. PR powinien edukować. Wielokulturowe, wieloetniczne, płynne, heterogeniczne zbiorowości zanurzone w świecie mediów mogą traktować PR-owców jak przewodników po świecie organizacji i potrzeb, jakie zaspokajają one u swoich interesariuszy.

Tezą, jaką stawia niniejsza praca, jest konieczność zadbania o wizualny obszar edukacji medialnej w odniesieniu do praktyk public relations organizacji. Wiele się pisze o skutkach reklamy, natomiast niewiele o działaniach PR, zwłaszcza inspirujących wymiar wizualny mediów. To PR może przyjąć rolę rozjemcy w starciu marketer organizacji kontra klient/odbiorca mediów. Otóż rzetelna instytucja, dbająca o etyczny wymiar swojego funkcjonowania, to także organizacja biorąca odpowiedzialność za estetyczny wymiar swoich przekazów ${ }^{24}$. Jak twierdzi Christoph

19 J. Olędzki, Etyka w polskim public relations, Oficyna Wydawnicza ASPRA-JR, Warszawa 2009.

${ }^{20}$ K. Wojcik, Public relations. Wiarygodny dialog z otoczeniem, Wolters Kluwers, Warszawa 2015.

${ }^{21}$ L. Edwards, Understanding Public Relations: Theory, Culture and Society, Sage, London 2018.

22 D. Holtzhausen, Postmodern Values in Public Relations, „Journal of Public Relations Research" 2000, t. 12 , nr 1, s. 93-114.

${ }^{23}$ R. Rukherjee, S. Banet-Weiser, Commodity Activism, New York University Press, New York 2012.

${ }^{24}$ Pisze o tym obszernie K. Chmielecki (2017), omawiając obszerną literaturę składającą się na kulturową teorię wizualności i widzenia. Zwłaszcza kwestie społeczeństwa spektaklu oraz konsumpcji obrazów medialnych wyjaśniają kontekst socjologiczny niniejszej pracy. 
$M_{e n k e}^{25}$, etyczne rozważania opierają się przede wszystkim na analizie otoczenia, na postrzeganiu sytuacji, przez co podmiot postrzega sam siebie. Świadomość uwarunkowań współczesnego funkcjonowania w kulturze obrazu ma w sobie przesłanki do informowania i opowiadania publicznościom o warunkach wyborów estetycznych. Zwłaszcza dla dzieci i młodzieży „samoobserwacja nie dokonuje się zazwyczaj w wyeksplikowanym akcie biograficznej refleksji, lecz za pośrednictwem reakcji na sytuację oraz odniesienie do niej"26. Wiedza na temat wpływu PR-u na zawartość mediów, szczególnie na ich wymiar estetyczny, jest dziś niezbędna do propagowania otwartości i dialogu z publicznościami. Ważne, aby w dyskusji z obszaru wizerunków medialnych i edukacji kłaść akcent na wizualny charakter dzisiejszej komunikacji public relations. Do takiego katalogu informacji dotyczących alfabetyzmu wizualnego odbiorców powinny wejść:

1. Blok PR: bazowa wiedza na temat PR-u, zwłaszcza jego wpływu na zawartość mediów i jego cechy dystynktywne w odróżnieniu od marketingu i jego narzędzi (szczególnie reklam); profesja PR-owca a profesja dziennikarza w kontekście wyboru ścieżki zawodowej przez młodzież; podstawowy słownik terminów, z akcentem na wyjaśnienie takich przekazów jak artykuł sponsorowany (ang. advertorial) i jego szata graficzna czy zdjęcia wizerunkowe produktów (ang. pack-shot); kwestia etyki w szokujących wizualnie kampaniach organizacji.

2. Blok wiedzy o komunikacji wizualnej: obrazy w mediach społecznościowych (tagowanie wizerunków, filtry na Instagramie); obrazy w mediach masowych (wizerunek prezentera telewizyjnego); trendy estetyczne (piękno w modzie dziecięcej i młodzieżowej).

3. Blok wiedzy dotyczący mechanizmów wpływu mediów i działań PR: wiedza wyróżniająca podstawowe narzędzia wpływu na dzieci i młodzież, której towarzyszyłoby omówienie przypadków współpracy PR-owców z blogera$\mathrm{mi}$, vlogerami, youtuberami; wydarzenia specjalne oraz muzea korporacyjne jako formy zbiorowej perswazji multimodalnej w przestrzeni publicznej (oczywiście w formie uproszczonej i omawiającej konkretne przykłady, np. obchodzenie urodzin w restauracji McDonald's czy wycieczka rodzinna do Muzeum Żywca lub wyjazd do muzeum marki takiej jak Lego).

Podział na trzy bloki strukturyzuje podstawowe obszary merytoryczne, które mogę lec u podstaw zwiększania zbioru kompetencji, jakim jest alfabetyzm wizualny. Warto, aby każdy blok wiedzy o estetycznym wymiarze PR-u i mediów obejmował bazowe informacje wraz z przykładami wskazujące podstawowe uwarunkowania psychologiczne i socjologiczne po stronie samych odbiorców, wymuszone centralnymi osiami ich współczesnego funkcjonowania, czyli estetyzacją, hedonizmem i konsumpcjonizmem. Dla młodych ludzi interesujące mogłyby być

${ }^{25}$ Ch. Menke, Życie na kształt dzieła sztuki?, [w:] K. Kaśkiewicz, R. Michalski, T. Siwiec (red.), Między etyka a estetyką. Rozważania nad problemem estetyzacji, Wydawnictwo UMK, Toruń 2017.

${ }^{26}$ Tamże, s. 168. 
zwłaszcza informacje o zagrożeniach dla psychiki jednostki, wynikające z przesadnego dbania o wizerunek. Liczne badania prowadzone wśród dziewczynek i młodych kobiet świadczą o palącej potrzebie w tym zakresie, dotyczą bowiem masowych sugestii medialnych skutkujących zaburzeniami odżywiania ${ }^{27}$. W wymiarze społecznym wiedzy z zakresu alfabetyzmu wizualnego i PR można natomiast przybliżyć, czym jest wizualna konsumpcja i jakie są jej przejawy wśród dzieci i nastolatków. Grupy te spędzają czas w centrach handlowych, uprawiając tak zwany window shopping, czyli odwiedzanie przestrzeni handlowych wyłącznie w celu czerpania przyjemności z oglądania, a nie samego zakupu produktów. To właśnie obcując z mediami indywidualnie i wspólnotowo, młodzi ludzie pozbawieni drogowskazów z opisem PR-owego uczestnictwa w kreowaniu treści medialnych są narażeni na manipulację i negatywny wpływ organizacji, wykorzystujących ich słabe kompetencje wizualne w zakresie recepcji i kreowania przekazów.

\section{Estetyzacja mediów a PR}

Wolfgang Welsch już w latach 90. XX wieku zauważył silny trend estetyzacji rzeczywistości społecznej, nie tylko w obszarze rozwoju sztuk wizualnych, ale również konstruowania estetycznej mediasfery. „Obrazy przekazywane przez media nie dają już gwarancji prawdziwości, są w dużej mierze aranżowane i sztuczne, coraz częściej też wirtualność przejawia się w sposobie prezentacji. Rzeczywistość w mediach staje się ofertą, która aż do głębi swej substancji jest wirtualna, daje się manipulować i przekształcać estetycznie" 28 . Media przenikają się wzajemnie, na potrzeby organizacji łączy je jednak często konkretny wybór estetyki, którą promują czy nawet lansują. Współczesne media po McLuhanie, Baudrillardzie, Flusserze i Postmanie nie mogą być traktowane jako materiał fizyczny czy obiektywny przekaźnik, a raczej jako pewien proces pośredniczący w relacji nadawca-odbiorcy. Często media wzmacniają empiryczną realność przez stałe konwencje wizualnej reprezentacji, czyli sam sposób prezentacji owego zapośredniczenia w zgodzie z interesem nadawcy instytucjonalnego może stanowić przedmiot badań. Jeśli przyjmiemy za Anną Zeidler-Janiszewską, że żyjemy w „zmediatyzowanej kulturze”29, i połączymy to $\mathrm{z}$ wiedzą na temat roli PR w kreowaniu owej kultury, wówczas odbiorca medium, dziś najczęściej wizualnego, jawi się jako konsument estetyki wybranej przez instytucje czerpiące $\mathrm{z}$ tego zysk.

27 S. Reaves, Rethinking Visual Ethics: Evolution, Social Comparison and the Media's Mono-Body in the Global Rise of Eating Disorders, „Journal of Mass Media Ethics” 2011, t. 26, nr 2, s. 114-134.

${ }^{28}$ W. Welsch, Procesy estetyzacji. Zjawiska, rozróżnienia, perspektywy, [w:] K. Zamiara, M. Golka (red.), Sztuka i estetyzacja. Studia teoretyczne, Wydawnictwo Fundacji Humaniora, Poznań 1999, s. $12-14$.

29 A. Zeidler-Janiszewska, Nowe media - pretekst do umiarkowanego optymizmu, [w:] K. Wilkoszewska (red.), Piękno w sieci. Estetyka a nowe media, Universitas, Kraków 1999. 
Konrad Chmielecki, badając zjawisko intermedialności, podkreśla, że samo „istnienie mediów zakłada możliwość wzajemnej wymiany, nie tylko informacji, ale także środków wyrazu, którymi media się posługują" ${ }^{30}$. Problem ten dotyka oczywiście licznych dyscyplin i dziedzin wiedzy, w niniejszej pracy zawężono go jedynie do wymiaru zawartości mediasfery inspirowanej przez komunikaty PR-owe, z akcentem na ich wiarygodność i transparentność, który to nacisk, jak wspomniano, odróżnia owe praktyki od jednokierunkowych, posprzedażowych komunikatów marketingowych. PR jest dialogiczny i na tym polega jego długoterminowa perswazyjność. Odpowiedzialny PR musi sprostać wymaganiom etycznym, jeśli ma gwarantować transparentność komunikacji i trwałość relacji. Warto, aby był proaktywny w informowaniu na temat wpływu estetycznego, jaki wywiera na młodych odbiorców, na dzieci. Te ostatnie nie posiadają nawet często kompetencji czytelniczych, obcują z mediami wyłącznie w wymiarze wizualnym, na przykład przez książki obrazkowe, gdzie bohater marki (m.in. Myszka Miki) uczy ich czytać i pisać. Propagowanie wiedzy na temat estetyzacji wpływu społecznego skierowanego do nieletnich powinno obejmować zwłaszcza organizacje, dla których takie publiczności są istotne, na przykład w przemyśle zabawkowym i rozrywkowym (PR dla przedsiębiorstwa Mattel czy korporacji Disney). Tam zarówno tworzenie wspólnot, jak i promowanie wzorców postępowania przez media mają istotny wymiar estetyczny.

\section{Katalog kompetencji podnoszących alfabetyzm wizualny obejmujący PR}

Małgorzata Wieczorek-Tomaszewska zwraca uwagę, że kształtowanie umiejętności człowieka w zakresie integracji doświadczeń zmysłowych, ze szczególnym uwzględnieniem wzroku, „ma fundamentalne znaczenie dla rozwoju nauki, ponieważ to one umożliwiają zintegrowanie postrzeganych wzrokowo prawdziwych lub sztucznie wygenerowanych obiektów, działań i symboli, występujących w otoczeniu człowieka"31. Autorka podkreśla hybrydowość koncepcji alfabetyzmu wizualnego. Nie tylko zasady komponowania samych obrazów, ale także łączenia ich z innymi przekazami werbalnymi z wykorzystaniem interdyscyplinarnego podejścia międzydziedzinowego są współcześnie koniecznością. Wizualizacje, wykresy, infografiki, fotografie, zestawienia statystyk wykorzystywane były od dawno w praktyce edukacyjnej ${ }^{32}$, obecnie jednak przybierają formę jeszcze bardziej angażującą

${ }^{30}$ K. Chmielecki, Estetyka intermedialności, Rabid, Kraków 2008.

${ }_{31}$ M. Wieczorek-Tomaszewska, Kompetencje wizualne w praktyce edukacyjnej, „Biblioteka i Edukacja. Elektroniczne Czasopismo Biblioteki Głównej Uniwersytetu Pedagogicznego w Krakowie" 2014, nr 5, s. 1.

${ }^{32}$ K. Coates, A. Ellison, An Introduction to Information Design, Laurence King Publishing, London 2014. 
w związku z rozwojem technologii cyfrowych i ich ustawiczną dostępnością. Temu rozwojowi nie towarzyszy pogłębiona edukacja w zakresie kompetencji niezbędnych do krytycznej analizy owych przekazów, na przykład odczytania manipulacji dzięki wykresowi wizualizującemu dane. Edukacja medialna w zakresie kompetencji wizualnych „dostarcza uczącemu się narzędzi umożliwiających zrozumienie i kontekstową analizę wizualnej przestrzeni kulturowej w oparciu o etyczne, estetyczne, intelektualne, techniczne elementy zaangażowane w tworzenie i stosowanie materiałów wizualnych"33.

Wieczorek-Tomaszewska wymienia siedem grup kompetencji wizualnych, opierając się na standardach amerykańskiego stowarzyszenia bibliotekarzy ACRL (Association of College and Research Libraries w ramach American Library Association) pod oryginalną nazwą „Visual Competency Standards for Higher Education”. Są to następujące katalogi kompetencji: (1) świadome zdefiniowanie potrzeb odbiorcy, (2) umiejętność znajdowania obrazów, (3) interpretacja i analiza obrazów, (4) ocena przydatności obrazów, (5) skuteczne wykorzystanie obrazów, (6) tworzenie własnych obrazów, (7) umiejętność etycznego cytowania materiałów wizualnych. Zakres wpływu PR na kompetencje odbiorcy obejmowałby katalog drugi, czyli wpływ organizacji na znajdowane obrazy (np. CEO i preselekcja w obrazach Google), a także trzeci (interpretacja obrazów), czyli kompetencje niezbędne do analizy kontekstu PR w nadawaniu znaczeń obrazom (np. promowanie wizerunku ambasadora organizacji). Wreszcie najistotniejszy $w$ ramach alfabetyzmu wizualnego katalog czwarty, czyli umiejętność oceny przydatności materiałów piktorialnych przez dzieci i młodzież. Zdolność ta obejmuje ocenę estetyki i wiarygodności źródła przekazu wizualnego oraz rozumienie przekształceń obrazów (np. przez filtry na Instagramie influencera). Warto podkreślić, że proces widzenia nie jest prostą recepcją bodźców, pasywnym aktem optycznym przyjęcia emitowanej fali światła na siatkówkę, lecz procesem kognitywnym, w którym procesy wiedzy zlokalizowane w korze mózgowej biorą aktywny udział ${ }^{34}$. Public relations wpływa na kształt wizualnych reprezentacji rzeczywistości, na proces konstruowania znaczeń obrazów, gdyż często kreuje estetykę przekazów medialnych, a także nadaje status obrazom. Chmielecki zauważa, że po zwrocie piktorialnym „komunikowanie za pomocą obrazu albo posługiwanie się jego »językiem « staje się równouprawnione $\mathrm{z}$ komunikowaniem tekstowym, którego funkcja zostaje zastąpiona przez kodowanie ikoniczne"35. Wydaje się, że medioznawstwo i PR mają przed sobą jeszcze długą drogę do przepracowania skutków zwrotu wizualnego w naukach oraz jego skutków społecznych.

${ }_{33}$ M. Wieczorek-Tomaszewska, Kompetencje wizualne..., dz. cyt., s. 3.

${ }^{34}$ P. Messaris, Visual Literacy: Image, Mind, and Reality, Westview Press, Boulder, CO 1994.

${ }^{35}$ K. Chmielecki, Widzenie przez kulturę, Wydawnictwo Naukowe Katedra, Gdańsk 2018. 


\section{Zakończenie}

Niniejsze opracowanie stanowi wprowadzenie z pogranicza edukacji medialnej, public relations oraz teorii komunikacji wizualnej, z akcentem na jej wymiar estetyczny i etyczny. Jest zbiorem postulatów do absorbującego zagadnienia odpowiedzialności i perswazyjności PR wobec dzieci i młodzieży oraz ich kompetencji piktorialnych, określanych jako alfabetyzm wizualny. Dialogiczny, transparentny PR organizacji, odpowiedzialny za ogromną część zawartości dzisiejszych mediów, winien odgrywać aktywną rolę w kształtowaniu umiejętności selekcji, oceny i interpretacji obrazów u dzieci i młodzieży zanurzonych w medialnym uniwersum stymulującym konsumpcję. Dewaluacja wymiaru estetycznego może mieć wpływ na etyczny wymiar funkcjonowania organizacji. Ciągła zmiana, lub raczej jej pozorowanie, dowolność w prezentacji w przestrzeni medialnej wizualnych rekwizytów budujących wizerunki medialne podmiotów dają wrażenie pluralizmu projektów wizualnych. Młodzi ludzie o niewystarczających kompetencjach, w ramach uczestnictwa w komunikacji wizualnej, mogą czuć się zagubieni lub pozorować eksperckość w dziedzinie, którą rządzą siły oraz nadawcy znajdujący się poza ich zrozumieniem i kontrolą. Odpowiedzialny PR zdejmuje maski. Artykuł wskazuje na trzy bloki wiedzy, które mogą być podstawą rozwoju alfabetyzmu wizualnego w wybranych katalogach kompetencji. W opracowaniu zostały one omówione wraz z przykładami tematów dla dzieci i młodzieży. Karol Sauerland, autor Estetyzacji świata, stwierdza wprost: „Człowieka możliwości można byłoby nazwać też człowiekiem estetycznym. Niektórzy uważają, że homo aestheticus stał się wzorem dla nowej generacji” ${ }^{36}$. Koncepcja aktywności PR w ramach edukacji medialnej w zakresie wiedzy o wizualności wymaga dalszych badań. Bez przyczynku do dyskusji, który stanowi niniejsza praca, trudno o praktyczne aplikacje w sferze zarządzania mediami wizualnymi.

\section{Bibliografia}

Chauvin B.A., Visual or Media Literacy?, „Journal of Visual Literacy” 2016, t. 23, nr 2, s. 119128.

Chmielecki K., Estetyka intermedialności, Rabid, Kraków 2008.

Chmielecki K., Widzenie przez kulturę, Wydawnictwo Naukowe Katedra, Gdańsk 2018.

Coates K., Ellison A., An Introduction to Information Design, Laurence King Publishing, London 2014.

Edwards L., Understanding Public Relations: Theory, Culture and Society, Sage, London 2018.

Filiciak M. (red.), Młodzi i media. Nowe media a uczestnictwo w kulturze, Raport Centrum Badań nad Kulturą Popularną SWPS, Warszawa 2010.

${ }^{36}$ K. Sauerland, Estetyzacja świata, [w:] K. Kaśkiewicz, R. Michalski, T. Siwiec (red.), Między etyka a estetyką. Rozważania nad problemem estetyzacji, Wydawnictwo UMK, Toruń 2017. 
Gałuszka D., Gry wideo w środowisku rodzinnym. Diagnoza i rekomendacje, Libron, Kraków 2017.

Goban-Klas T., Edukacja medialna. Społeczeństwo medialne, WSiP, Warszawa 2005.

Holtzhausen D., Postmodern Values in Public Relations, "Journal of Public Relations Research" 2000, t. 12 , nr 1 .

International Visual Literacy Association, https://ivla.org/new/what-is-visual-literacy-2/.

Kąkolewicz M., Edukacja medialna - nowa dziedzina kształcenia, „Edukacja Medialna” 1999, nr 4.

Melosik Z., Szkudlarek T., Kultura, tożsamość i edukacja. Migotanie znaczeń, Impuls, Kraków 1998.

Menke Ch., Życie na kształt dzieła sztuki?, [w:] K. Kaśkiewicz, R. Michalski, T. Siwiec (red.), Między etyka a estetyką. Rozważania nad problemem estetyzacji, Wydawnictwo UMK, Toruń 2017.

Messaris P., Visual Literacy: Image, Mind, and Reality, Westview Press, Boulder, CO 1994.

Miotk A., Nowy PR. Jak internet zmienił public relations, Słowa i Myśli, Lublin 2016.

Ogonowska A., Ptaszek G. (red.), Edukacja medialna $w$ dobie współczesnych zmian kulturowych, społecznych i technologicznych, Impuls, Kraków 2015.

Olędzki J., Etyka w polskim public relations, Oficyna Wydawnicza ASPRA-JR, Warszawa 2009.

Olędzki J., O wizerunku public relations w polskim społeczeństwie, „Studia Medioznawcze” 2016 nr 1/64, s. 23-35.

Olędzki J., Tworzydło D., Public relations. Znaczenie społeczne i kierunki rozwoju, WSIiZ, Wydawnictwo Naukowe PWN, Rzeszów-Warszawa 2010.

Reaves S., Rethinking Visual Ethics: Evolution, Social Comparison and the Media's Mono-Bo$d y$ in the Global Rise of Eating Disorders, „Journal of Mass Media Ethics” 2011, t. 26, nr 2, s. 114-134.

Rukherjee R., Banet-Weiser S., Commodity Activism, New York University Press, New York 2012.

Sauerland K., Estetyzacja świata, [w:] K. Kaśkiewicz, R. Michalski, T. Siwiec (red.), Między etykq a estetyką. Rozważania nad problemem estetyzacji, Wydawnictwo UMK, Toruń 2017.

Siuda P., Stunża G.D., Dąbrowska A.J., Klimowicz M., Kulczycki E., Piotrowska R., Rozkosz E., Sieńko M., Stachura K., Dzieci sieci 2.0. Kompetencje komunikacyjne młodych, Instytut Kultury Miejskiej, Ośrodek Badań i Analiz Społecznych, Gdańsk 2013.

Starakiewicz M., Obraz jako argument w humanistyce, "Zagadnienia Rodzajów Literackich” 2017, $\mathrm{nr} 3$.

Strykowski W., Media i edukacja, „Edukacja Medialna” 1996, nr 1.

Stunża G.D. (red.), Edukacja kulturalna i medialna. Nowe trendy i wyzwania, Edukatormedialny.pl, Instytut Kultury Miejskiej, Gdańsk 2014.

Waszkiewicz-Raviv A., Niepublikowany raport z badań „Materiały wizualne w PR kultury obrazu" przeprowadzonych na próbie specjalistów PR i zarządzania mediami w czasie ogólnopolskiego seminarium „Kondycja branży PR w Polsce” w listopadzie 2017 roku.

Welsch W., Estetyka i anestetyka, [w:] R. Nycz (red.), Postmodernizm. Antologia przekładów, Wydawnictwo Baran i Suszczyński, Kraków 1998.

Welsch W., Procesy estetyzacji. Zjawiska, rozróżnienia, perspektywy, [w:] K. Zamiara, M. Golka (red.), Sztuka i estetyzacja. Studia teoretyczne, Wydawnictwo Fundacji Humaniora, Poznań 1999.

Wieczorek-Tomaszewska M., Kompetencje wizualne w praktyce edukacyjnej, „Biblioteka i Edukacja. Elektroniczne Czasopismo Biblioteki Głównej Uniwersytetu Pedagogicznego w Krakowie" 2014, nr 5.

Wojcik K., Public relations. Wiarygodny dialog z otoczeniem, Wolters Kluwers, Warszawa 2015. 